\title{
COMPARATIVE STUDY REGARDING THE WELDING BEHAVIOR OF GALVANIZED STEEL USING LASER WELDING AND GAS METAL ARC WELDING PROCESSES
}

\author{
B. Yavuz*, M. Vural \\ Istanbul Technical University, Department of Mechanical Engineering, Istanbul, Turkey \\ *Corresponding author’s e-mail address: basaryavuzz@gmail.com
}

\begin{abstract}
Gas metal arc welding (GMAW) and laser welding are two commonly used joining methods. In this study, these two welding methods were used to join the galvanized sheets. For GMAW, the process parameters were: welding wire diameter, shielding gas flow, welding speed, current and wire feed speed. In term of laser welding, the analyzed parameters were: welding speed, power and pulse duration. In order to establish the effects of the main parameters on the resistance of the welded joint, changes were made to the values of a single process parameter, and the others were kept constant. The combined welded samples were examined non-destructively using $X$-rays method and then were subjected to destructive tensile tests, analyzing the tensile strength values.
\end{abstract}

KEYWORDS: laser welding, gas metal arc welding, galvanized steel, X-ray examination, tensile testing.

\section{INTRODUCTION}

Steels are iron-based products and they are used in industry because of their high mechanical properties and suitability for various manufacturing methods. However, they are unresisting to external effects.

The most damaging factors for iron-based products are moisture and wet environment. Exposing to moisture of iron-based products causes to shorten their lifetime and getting lose their properties and strength within a few years. To overcome this unwanted situation, steels are coated with zinc and this process is also called as galvanizing. Galvanizing process helps products to fulfill their function in many years. Galvanized sheets are find a widespread usage area due to their high corrosion resistance. However, the low boiling temperature of zinc causes the zinc coating to evaporate and the corrosion resistance starts to decrease during the welding of galvanized sheets. This situation significantly affects the quality of the welded structure and damages the reliability of the welding operation. There are many welding techniques used in the galvanized steel sheets such as laser welding and gas metal arc welding (GMAW).

Automotive industry tries to make car weights lighter to reduce the energy requirement. Galvanized steel sheets are one of the main solution for this purpose, because they can be produced thinner. In the manufacturing operations, welding is the key method for high quality joining. Modern car has almost 5000 resistance spot welding point in its body [1]. There are some obstacles in the welding of galvanized steel with resistance spot welding. The high value of the current and the welding time that characterize the spot welding process determine the reduction of the good functioning period of the copper electrodes. This situation increases the maintenance cost of the operation [2]. Especially in the galvanized steel sheets, some other welding techniques can be considered with some of their advantages.

The specific welding conditions involve the localized high heat value, which causes the evaporation of zinc layers deposited on steel surfaces. There is research showing that, during welding operations on galvanized steels, the quality of welds is affected due to zinc vapors coming from the coating layers, which form brittle compounds [3], [4]. There are some researches to overcome and understand these situations.

In recent years, additive manufactured laser applications, which are used as a type of laser welding process, are widely observed. In the study, the effect of producing samples with this method on the mechanical properties was investigated. As a result, it has been observed that there is no change in the mechanical properties of the parts produced by this method according to the loading direction or the production direction [5]. In another study, materials produced by laser metal deposition process were used.

The study tried to understand the relationship between the amount of tungsten powder and the microstructure. As a result of the study, it was 
revealed that tungsten carbide showed an even and uniform distribution in the microstructure [6].

GMAW is one of the techniques used for welding galvanized steel sheets, for which different methods have been tested to improve welding behavior. Some of the researchers have tried to modify the shielding gas content.

In one of the works, Matsui et al. try to understand how oxygen addition affect the quality of zinc coating in welding. They found that oxygen addition makes harder to evaporate of zinc coating, because adding oxygen creates zinc oxides which has a high boiling point [7]. Porosity in welding pool occurs when the zinc starts to evaporate. In parallel to this knowledge, Ahsan et al. shows that decreasing the porosity in the welding operations are related to the heat input [8].

Raveendra and Parmar create mathematical model to predict the welding quality, dilution and the shape of weld bead. With this technique, they thought that the control of welding conditions during production could be done better [9]. Wei et al. used statistical methods. In the research, they try to predict surface porosity in the gas metal arc welding operation [10].

Laser welding is a new technique in welding history. However it has many advantages, such as; high energy density, minimum distortion with narrow heat affected zone (HAZ) [11]. During the welding operation, the high energy is focused in a restricted area, which limits the extensive damage to neighbouring areas. However, zinc coating is a problem for laser welding, as well. Researchers show that during the laser welding operation, keyhole instability is observed because of zinc coating evaporation. They also showed, the diameter of the keyhole is changing during the operation [12].

Mei et al. show that the welding by fiber laser gives higher tensile strength than the welding by $\mathrm{CO}_{2}$ laser. $\mathrm{CO}_{2}$ laser uses higher wavelength laser, therefore, less energy can be transferred to the workpiece. Rest of the energy is absorbed by the flux [13]. Akio et al. investigated the hardness and softening in the heat affected zone. They found this area is small due to the narrow heat affected zone in laser welding which is focused the energy in a small area [14].

Anawa and Olabi investigated the tensile strength of laser welded ferritic/austenitic steel parts. They concluded that increasing in power density and decreasing in welding speed cause increasing in tensile strength [15].

Katayama and Mizutani try to investigate the effect of different laser type on welding defect and dilution in the different aluminum alloys. They focused in investigating the porosity formation. They found increasing in welding speed decrease the formation amount and dimension of the porosity [16].

In recent years, studies have been carried out on the use of various laser welding methods instead of the traditional gas arc welding method. In one of these studies, the use of local vacuum electron beam welding method instead of MAG was investigated in order to increase production efficiency. The study showed that in the samples combined with local vacuum electron beam welding, the areas with welding residual stress were observed to be in a narrower area. In addition, experiments and simulations have shown that samples welded with MAG have higher residual stress values than those combined with local vacuum electron beam welding [17].

The use of laser welding and hybrid laser arc welding has also been studied extensively in recent years. In this context, HG785D steel was welded with laser welding and laser-arc hybrid welding and then examined in terms of microstructure and mechanical properties. As a result, different microstructures were observed due to high heat input in the hybrid method. In addition, lower micro hardness and higher impact energy value were observed in the welding zone in the hybrid method [18].

In another study on laser hybrid welding, the effect of changes on the heat source on the sample was investigated. In the study, the distance between the laser beam and the electrode tip and the laser guidance mode were changed. In the study, it was observed that the distance between the laser beam and the electrode tip is important and when this distance reaches a value more than the ideal range, scattering occurs in the beam and an increase in the rate of welding defects [19].

In another study for hybrid laser-MAG welding, real-time observation of droplets and electrical signals generated during the welding process was aimed. A high speed camera was used to observe this situation. The study observed that both laser power and arc power affect the weld depth and quality. They concluded that by setting a correct distance between the laser and the arc, the quality of the weld would be positively affected, with less effect of spattering droplets on the keyhole [20].

In this study, the effect of laser welding and gas metal arc welding on the mechanical properties of galvanized steel sheets and porosity formations are investigated. The study aims to examine the effects of the values of welding parameters on the strength of welded joints made of galvanized sheets.

\section{MATERIALS AND METHODS}

Galvanized steel sheet with a thickness of $1 \mathrm{~mm}$ is used as a workpiece in this study. The material is commercially available on the market and widely used in industry. All the specimens have a 30x100 $\mathrm{mm}$ dimensions with a thickness of $1 \mathrm{~mm}$ and the specimens' dimensions can be seen in figure 1 . The specimens are butt welded in the face of $30 \mathrm{~mm}$ length. 
In the experimental study, both laser welding and GMAW are used. Table 1 shows the parameters of GMAW and parameters of laser welding can be seen in Table 2.

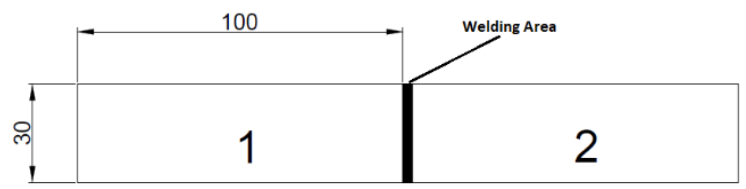

Fig. 1. Test specimen dimensions

Table 1. Welding parameters of GMAW

\begin{tabular}{|c|c|c|c|c|c|}
\hline $\begin{array}{c}\text { Specimen } \\
\text { Number }\end{array}$ & $\begin{array}{c}\text { Welding Wire } \\
\text { Diameter }[\mathbf{m m}]\end{array}$ & $\begin{array}{c}\text { Shielding } \\
\text { Gas Flow } \\
\text { Rate }[\mathbf{1} / \mathbf{m i n}]\end{array}$ & $\begin{array}{c}\text { Welding } \\
\text { Speed } \\
{[\mathbf{m m} / \mathbf{s}]}\end{array}$ & $\begin{array}{c}\text { Current } \\
{[\mathbf{A}]}\end{array}$ & $\begin{array}{c}\text { Wire } \\
\text { Feed } \\
\text { Speed } \\
{[\mathbf{m} / \mathbf{m i n}]}\end{array}$ \\
\hline 1 & 0.8 & 12 & 2 & 2.2 & 7 \\
\hline 2 & 0.8 & 12 & 2 & 2.4 & 7 \\
\hline 3 & 0.8 & 12 & 2 & 2.6 & 7 \\
\hline 4 & 0.8 & 12 & 3 & 2.2 & 7 \\
\hline 5 & 0.8 & 12 & 4 & 2.2 & 7 \\
\hline 6 & 0.8 & 12 & 4 & 2.2 & 8 \\
\hline 7 & 0.8 & 12 & 4 & 2.2 & 9 \\
\hline 8 & 0.8 & 14 & 2 & 2.2 & 7 \\
\hline 9 & 1.2 & 12 & 2 & 2.2 & 7 \\
\hline
\end{tabular}

Table 2. Welding parameters of laser welding

\begin{tabular}{|c|c|c|c|}
\hline $\begin{array}{c}\text { Specimen } \\
\text { Number }\end{array}$ & $\begin{array}{c}\text { Welding } \\
\text { Speed [mm/s] }\end{array}$ & Power [W] & $\begin{array}{c}\text { Pulse } \\
\text { Duration [ms] }\end{array}$ \\
\hline 1 & 1 & 180 & 3 \\
\hline 2 & 1 & 180 & 4 \\
\hline 3 & 1 & 180 & 5 \\
\hline 4 & 1 & 180 & 6 \\
\hline 5 & 1 & 180 & 7 \\
\hline 6 & 1 & 200 & 3 \\
\hline 7 & 1 & 220 & 3 \\
\hline 8 & 1 & 240 & 3 \\
\hline 9 & 1 & 260 & 3 \\
\hline 10 & 1.5 & 180 & 3 \\
\hline
\end{tabular}

All specimens are examined in the X-ray examination. All specimens are tested in Examination Standard TS EN ISO 17636-1 and evaluated in Evaluation Standard TS EN ISO 10675-1. GEERSCO brand $52 \mathrm{MF} 4 \mathrm{CL}$ type $\mathrm{x}$-ray equipment used in $100 \mathrm{kw}, 6 \mathrm{~mA}$ and $0.5 \times 5.5 \mathrm{~mm}$ focus size. During $\mathrm{X}$-ray examination, the focusing distance of the film was of $650 \mathrm{~mm}$ and the exposure time was of $100 \mathrm{~s}$, as can be seen in figure 2. After the testing procedure, all films are examined and weld defects are detected.

During the tensile testing procedure, specimens were clamped and force is applied until the specimen reached the fracture point by using the tensile test machines Shimadzu AG-IS $50 \mathrm{kN}$. The sample dimensions for tensile test are presented in Figure 1. Using the tensile test machine, the evolution of stresses and strains were analyzed in connection with the chosen values of welding parameters.

The tests were performed on 3 identical samples and the test results used were taken from the average of the results of 3 samples.

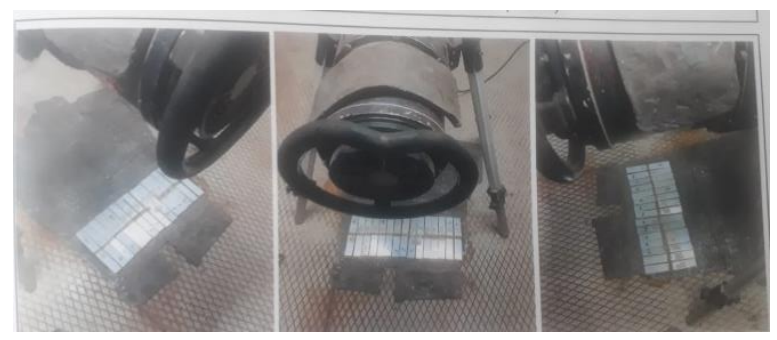

Fig. 2. Radiographic testing of samples

\section{RESULTS AND DISCUSSIONS}

The X-ray examination method allows highlighting defects such as lack of penetration and porosity, which are the main problems that affect the weld quality in the case of GMAW welding process. Even the best visual specimen has also some welding defect according to X-ray films.

In the first part of the study, for understanding the effect of wire feed speed on porosity and welding defects, the other parameters were kept constant. Therefore, specimens 5, 6 and 7 are used. According to $\mathrm{X}$-ray films, lack of penetration is the main defect. It is seen that with the increase in the feed rate of the welding wire, the time required for the melting of the welding wire cannot be reached and in this case it causes the welding penetration to be negatively affected. Welding penetration decreases with increasing the wire feed speed above a certain speed.

The change in wire feeding speed causes changes in other parameters. Current intensity, melting power and profile of the weld area are in a highly correlated relationship with wire feed rate. Shielding gas flow rate $12 \mathrm{l} / \mathrm{min}$ and $14 \mathrm{l} / \mathrm{min}$ were used to perform the specimen 1 and 8 . Specimen 8 shows the existence of clustered porosity and specimen 1 exhibits gas pore (Fig. 3).

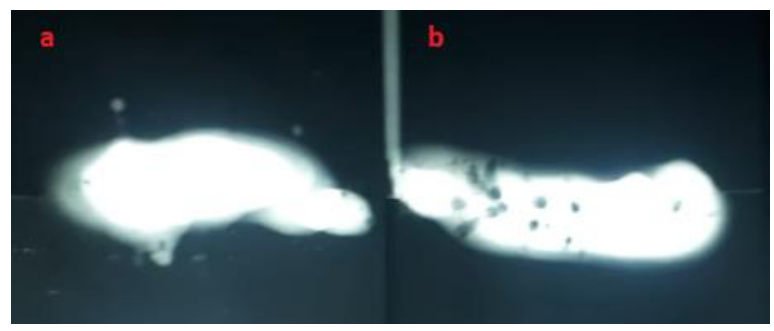

Fig. 3. X-ray films of specimens welded by GMAW a) gas pore b) clustered porosity

The increase in gas flow rate caused gas stuck and increased porosity in the weld pool. Specimen 1 , 4 and 5 are used to understand the effect of welding 
speed. In this part, 3 welding speed are used which are 2, 3 and $4 \mathrm{~mm} / \mathrm{s}$. Specimens welded by GMAW are done by experienced welder. According to x-ray films, when welding is done with $2 \mathrm{~mm} / \mathrm{s}$, melting and burning is observed in the welding area, in addition to this, the presence of gas holes is determined. The welding quality is better in $3 \mathrm{~mm} / \mathrm{s}$ welding speed. However, some porosity is also observed in this case. In the process performed at $4 \mathrm{~mm} / \mathrm{s}$ speed, a lack of penetration was observed as the time required for melting of the material was insufficient.

Change in welding speed causes change in welding current. This situation indirectly affects the penetration. A lower welding speed than necessary causes a lack of penetration, while high welding speed has a negative effect on welding penetration. In addition, the shielding gas could not fulfill its task at high welding speeds. In such cases, the protection of the weld metal cannot be achieved. In the long term, oxidation is likely to occur. One of the other important parameter is current and specimen 1,2 and 3 are used for understanding the effect of it. Current is related with the heat generation during the welding operation.

In cases where low current is applied, welding dilution is occurred due to insufficient heat generation. On the other hand, the application of high current causes the temperature to increase rapidly and the galvanized coating evaporates and the steel is open to corrosion. It also increases in porosity at high current values due to the evaporating zinc coating. The most important parameter affecting the weld penetration is the welding current. Welding process performed faster than required for the welding current causes the formation of undercut in the welding area.

The last parameter is the diameter of the welding wire. Two types of wire are used to weld specimen 1 and 9. Wire diameters are $0.8 \mathrm{~mm}$ and 1.2 $\mathrm{mm}$, respectively. When larger and smaller diameters are tested at the same current level, it is seen that the smaller diameter has better welding dilution. Because the diameter of the wire affects the melting power and thin wires have higher melting power at the same current value. When the cross-sections of both wires are examined, it is seen that the wire with a lower diameter has less cross-sectional area. Therefore, at the same Volt/Ampere power, thinner wire sections are loaded specifically (per unit section) with higher current.

As a result of this intense current, welding dilution rate is better when of smaller diameter is used for welding. However, there is a maximum current density value for each welding wire diameter, which makes the welding operation unstable and variable. Therefore, when the current reaches a certain value, it becomes necessary to increase the diameter of the welding wire. In the study, specimen 9 which is welded by a bigger diameter wire causes the lack of penetration. For the small thickness of workpiece, the diameter of the welding wire should be selected as small.

Laser welding parts are observed in x-ray, as well. Welding speed, power and pulse duration are selected as the experimental parameters. The laser welding process was carried out by a technician with a semi-automatic machine. Welding speed values are measured as $1 \mathrm{~mm} / \mathrm{s}$ and $1.5 \mathrm{~mm} / \mathrm{s}$. X-ray films show that porosity and other welding defects in laser welding are less than in samples welded by GMAW. However, some porosities are observed because of the low boiling temperature of the zinc coating. During the welding process, a decrease in the porosity ratio was observed by increasing the power (specimen 6, 7, 8, 9 and 1).

With high power, the time required for the solidification of the weld pool increases. This long period provides enough time for the gases in the welding area to evaporate. The increase in the power value during the welded joint is another factor affecting the tensile strength of the welded structure. Increased power values mean more heat input to the structure. This situation causes a decrease in the mechanical properties of the combined material and a deterioration in the strength values of the welded specimen.

Increasing in welding speed with no changing in power, causes to increase in porosity formation. Because, with the increase in laser welding speed, the amount of energy received per unit area will decrease. In this case, the solidification of the weld pool will accelerate and the gases will be trapped in the weld pool (specimen 1 and 10). These gases will appear as an increase in porosity in the weld. In addition to this, in the laser welding process, the increase in the welding speed changes the morphology of the welded area. This situation causes an increase in hardness. High hardness values usually appear as an increase in tensile strength.

An increase in the cooling rate is observed with the increase in welding speed. In this case, a finergrained structure formation is observed in the weld zone. This fine-grained structure appears as an increase in strength values. Pulse duration is a parameter that shows how long the beam is in contact with the workpiece. Increasing in pulse duration creates higher transferred energy. That condition increases the heat affected zone of the welding area. HAZ region widening is seen at high pulse duration values. This situation manifests itself as a decrease in tensile strength and other mechanical properties.

The increase in pulse duration means that the unit of energy transferred to the workpiece takes in a longer time. In this case, since the time required for the material to solidify will be longer, more time will be provided for the gases in the welding area to diffuse. It can be interpreted that this situation decreases the formation of porosity (specimen 1, 2, 3, 4 and 5). All the specimens for both laser welding and GMAW are tested in the tensile testing machine. 
Load- extension graphs are created. The graphs are also arranged by parameters in order to illustrate the effect of the welding parameters on the strength. Laser welding load- extension graph can be seen in figure 4. As can be seen in the graph of the test, the values of some samples gave close results. These values are shown in detail during the explanation of the effects of the parameters. Samples before and after the tensile test can be seen in figure 5 for GMAW and figure 6 for laser welding.

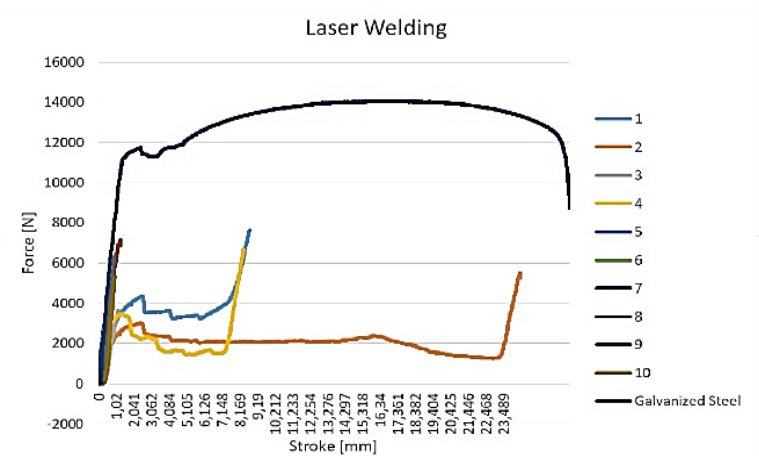

Fig. 4. Load vs. extension of galvanized steels specimens and specimens welded by laser welding

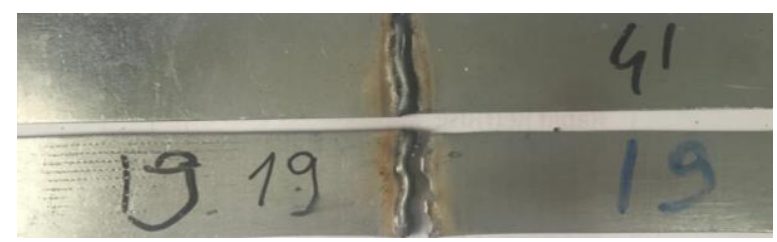

Fig. 5. Samples welded by GMAW before and after the tensile testing

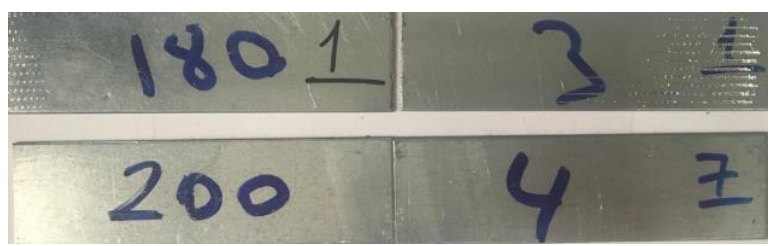

Fig. 6. Samples welded by laser welding before and after the tensile testing

During the test, there were cases where the pulling operation showed some slippage between the clamping head and the material. These situations appear in the graphs as parallel regions where the force value does not change.

When looking at the samples joined by laser welding, it can be said that the welding quality is good. However, the tensile test results show that the strength values of the regions joined by welding have given values below the strength values of the base metal. In the sample number 1 , which has the highest strength value in the joints made by laser welding, the value approaches $8000 \mathrm{~N}$. Although the $8000 \mathrm{~N}$ value is the highest value in the tests, it remains lower than the $12000 \mathrm{~N}$ which is the base metal value.
If we look at the effects of the parameters separately, the increase in the welding speed caused a decrease in the strength value. The reason for this situation can be shown that the amount of heat required for the melting of the material at high welding speed is not fully transmitted. With the high welding speed, the amount of heat transmitted per unit time will decrease. This situation appears as a decrease in strength and this situation can be seen in figure 7 .

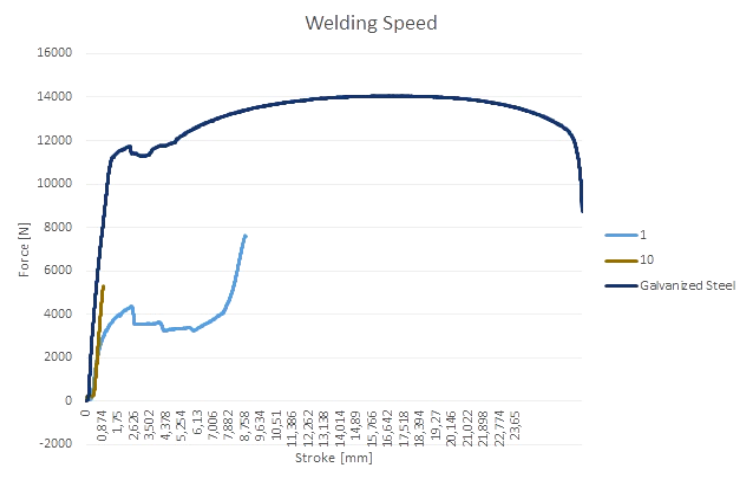

Fig. 7. Welding speed effect on mechanical strength of specimen 1 and 10 welded by laser welding

In figure 8 , the effect of the change in the power values on the strength values is shown. With increasing power value, the amount of energy transferred to the material increases in direct proportion. In the sample number 1, insufficient melting due to low power occurred and this situation manifested itself with low strength value.

However, when looking at samples numbered 7 and 8 , which are around the optimum value, it was seen that the strength values were close to each other. If higher values were applied, it is expected that a decrease in strength values would be observed with a change in the morphological structure of the material due to the high heat input.

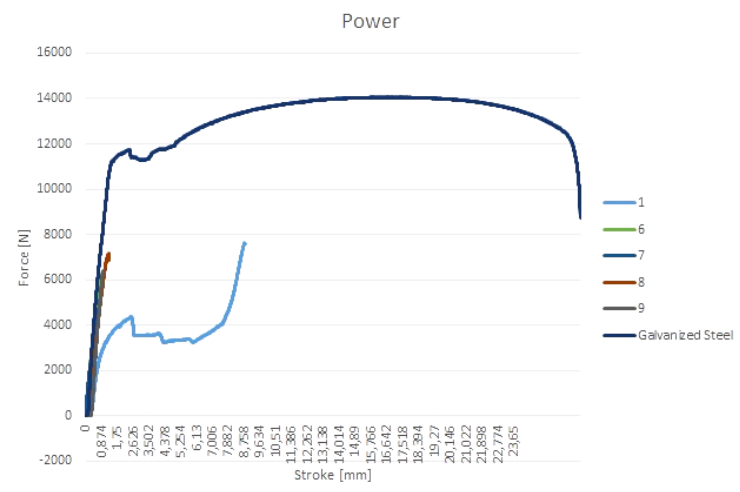

Fig. 8. Power effect on mechanical strength of specimen 1, 6, 7, 8 and 9 welded by laser welding

When we look at the effect of the pulse duration on the strength of the weld zone, it turns out that the 
increased contact time causes a slight decrease in the strength values. The reason for this situation can be demonstrated by the long contact time and the proportional increase in the amount of heat transferred and as a result, the growth of HAZ. This situation can be seen in figure 9 .

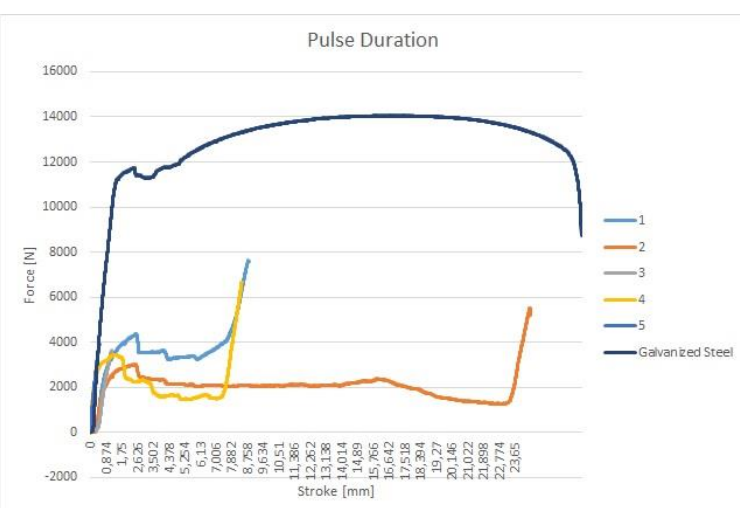

Fig. 9. Pulse duration effect on mechanical strength of specimen 1, 2, 3, 4 and 5 welded by laser welding

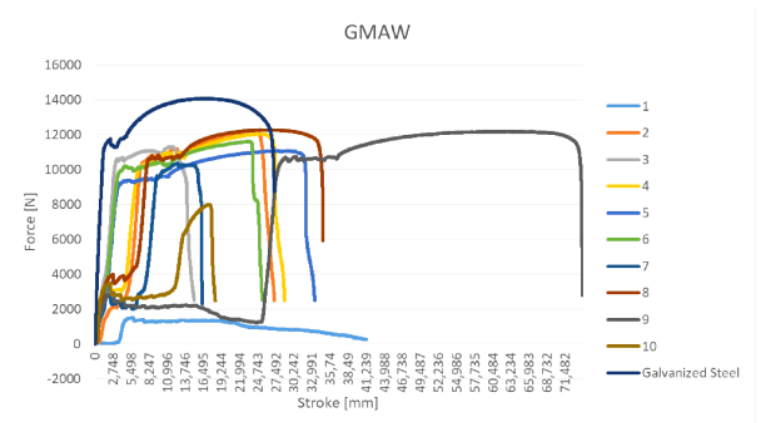

Fig. 10. Load vs. extension of specimens of galvanized steels and specimens welded by GMAW

As in the tests of laser-welded samples, there was some slippage between the head and the sample in GMAW samples. The results of tensile tests for samples welded with the GMAW process can be seen in Figure 10. Sample 1 demonstrated its poor welding quality in a tensile test. The highest force values it can withstand remained below $2000 \mathrm{~N}$. Especially, the force values around $12000 \mathrm{~N}$ obtained in the samples numbered 8 and 9 are very successful results. However, no test sample could reach the $14000 \mathrm{~N}$ values that galvanized sheet can withstand. For GMAW, 5 different parameters were examined. The graphs of the tensile test of the samples belonging to these parameters were examined separately.

Considering the effect of the diameter of the welding wire on the strength values, it was thought that the increasing diameter would cause a decrease in the strength value and it can be seen in figure 11 . However, since insufficient melting was observed in the sample produced with small diameter welding wire, the tensile strength value was found to be lower. Since the small diameter welding wire would have a higher melting power at the same current value, it was expected that the smaller diameter wire would give a better value before the test.

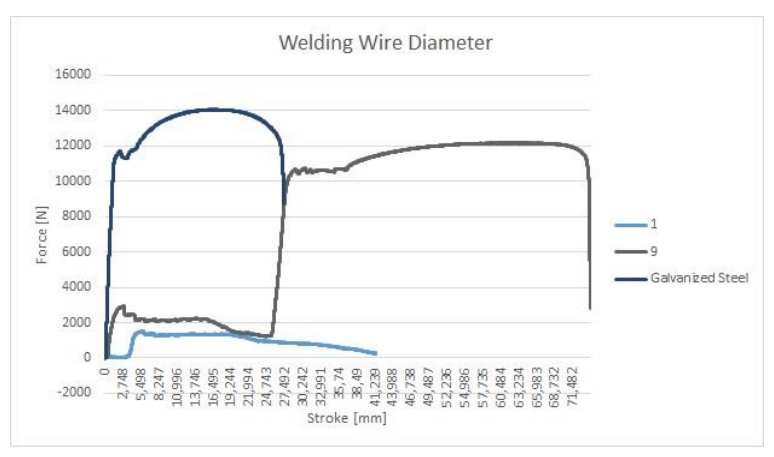

Fig. 11. Welding wire diameter effect on mechanical strength of specimen 1 and 9 welded by GMAW

Shielding gas flow is another influence parameter on the weld quality. When we look at the effect of this parameter, an improvement was observed in the strength values with the increasing amount of protective gas (figure 12). The reason for this situation can be shown as the better protection of the welding area against external factors. Sufficient shielding gas flow is essential for a quality welding process.

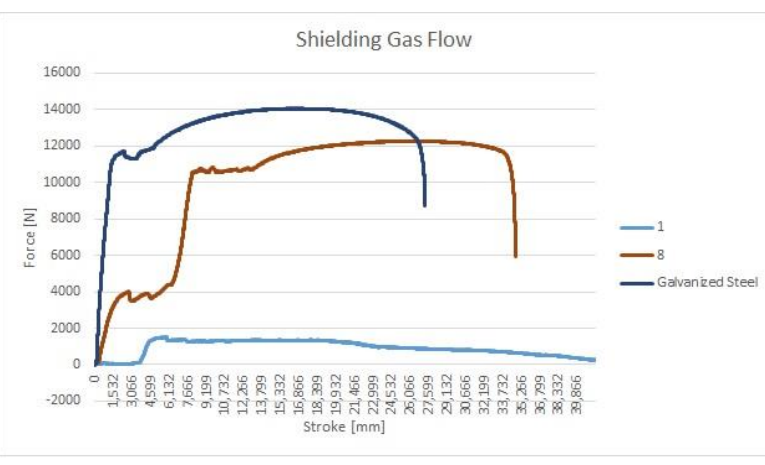

Fig. 12. Shielding gas flow effect on mechanical strength of specimen 1 and 9 welded by GMAW

Welding speed is an important parameter that determines the welding quality. At low welding speeds, high melting occurs in the material and the material is damaged. Processes performed at high welding speeds result in insufficient melting. The graph that plots the evolution of the tensile strength as function of welding speed is shown in figure 13. In the sample number 1 , which was combined with low welding speed, holes were formed and strength values decreased. In the samples numbered 4 and 5, medium and high speed joining was performed, respectively.

As can be seen in the graph, the strength values in the high speed process are slightly lower than the medium speed process. As can be seen from this result, welding speed should be applied at optimum values in order to reach high strength values. 


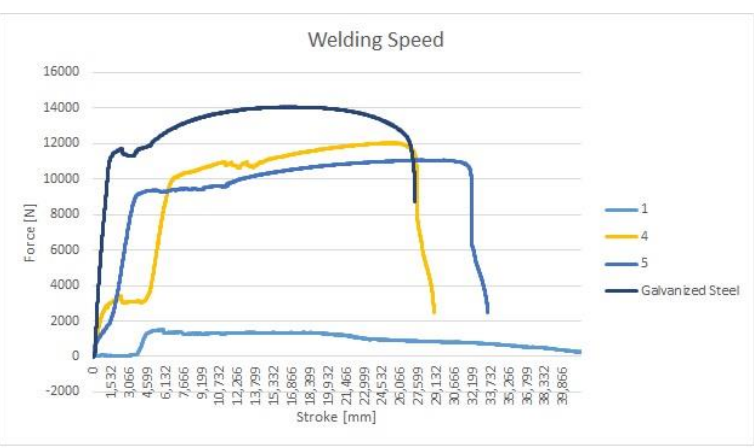

Fig. 13. Welding speed effect on mechanical strength of specimen 1, 4 and 5 welded by GMAW

The amperage is an important parameter as it is related to the amount of heat generated during the welding process. As seen in sample number 1, insufficient amount of melting was observed due to insufficient current. This is seen as a decrease in strength values. The current values of samples 2 and 3 are relatively more ideal values. These results are obtained from the high values in the strength values. The strength values reached in the test of samples 2 and 3 were approximately the same and measured slightly more than $10000 \mathrm{~N}$ (figure 14).

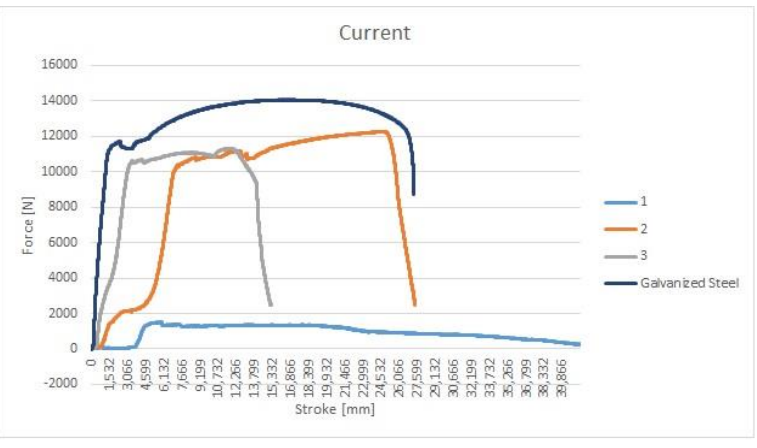

Fig. 14. Welding current effect on mechanical strength of specimen 1, 2 and 3 welded by GMAW

When the wire feed speed is high, it causes the welding material to pile up, and when it is low, it causes insufficient welding material. If we look at the test results, the tensile strength value for the 5th sample is lower than the other samples. This can be explained by the low welding wire speed and, consequently, an inadequate joint. In the other 2 samples, it appears as higher tensile strength results as the wire feed speed is sufficient (figure 15).

According to these results, a good quality bonding process can be done with GMAW with the right parameters. In laser welding, it is seen that the welding area is a little weaker. Samples joined by laser welding gave mostly good quality results. On the other hand, the ability of the welder is also important in the joints made with GMAW. This makes the GMAW source quality more prone to human error.

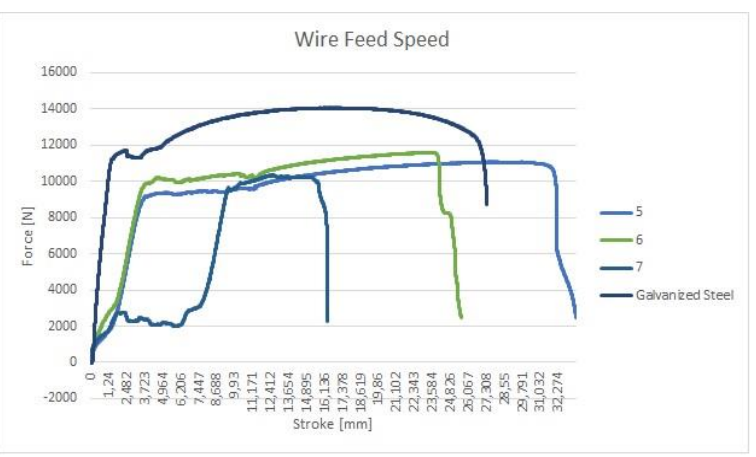

Fig. 15. Wire feed speed effect on mechanical strength of specimen 5, 6 and 7 welded GMAW

\section{CONCLUSIONS}

The study investigated the effect of laser welding and gas metal arc welding on the porosity formation and mechanical properties of the galvanized steel sheets. Process parameters of laser welding in this study are selected as welding speed, power and pulse duration. The other welding method is gas metal arc welding and parameters for the study are selected as welding wire diameter, shielding gas flow rate, welding speed, current and wire feeding speed. X-ray films show that for the GMAW, porosity and some other welding defects are the main problems.

It is observed that joints made by GMAW are stronger in terms of mechanical properties than those made by laser welding. This result can be seen in the load- extension graphs easily. As a result, the use of GMAW while welding galvanized sheets provides benefits to the structure in terms of mechanical properties. However, it is an undeniable fact that the large heat affected zone during GMAW caused more damage to the galvanized coating. This leads to the conclusion that the resistance to corrosion will be worse for samples combined with GMAW.

In order to reduce the porosity caused by the gases in the welding area, welding parameters should be selected carefully, that will provide sufficient time for the gases in the weld pool to evacuate.

\section{REFERENCES}

[1] Chao Y., Failure mode of spot welds: interfacial versus pull out, Sc.Technol.Weld.Join, pp. 133-137, 2003.

[2] Holliday R., Parker J., Williams N., Relative contribution of electrode tip growth mechanism in spot welding zinc coated steels," Welding Int., pp. 186-193, 1996.

[3] Ahsiri R., Haque M., Ji C., Shamanian M., Salimijazi H., Park Y., Supercritical area and critical nugget diameter for liquid metal embrittlement of Zn-coated twining induced plasticity steels, Scripta Materialia, vol. 109, pp. 6-10, 2015.

[4] Ahsiri R., Shamanian M., Salimijazi H., Haque M., Bae J., Ji C., Chin K., Park Y., Liquid metal embrittlement-free welds of Zn-coated twinning induced plasticity steels, Scripta Materialia., vol. 114, pp. 41-47, 2016.

[5] Rosenthal Y., Apelstein Y., Rosenthal I., Ashkenazi D., On Laser powder-bed fusion of additively manufactured AlSilOMg alloy: tensile properties and structure characterisation, Annals of "Dunarea de Jos" University of Galati. Fascicle XII: Welding 
Equipment and Technology, vol. 30, pp. 5-12, 2019.

[6] Adeyemi A., Akinlabi E., Mahamodd R., Microstructural evolution of laser metal deposited 17- 4 PH SS-tungsten composite with varying volume percent tungsten, Annals of "Dunarea de Jos" University of Galati. Fascicle XII: Welding Equipment and Technology, vol. 29, pp. 41-46, 2018

[7] Matsui H., Suziki H., Yamada M., Reduction of blowholes in high-speed arc welding of hotdip galvanized steel sheets, Welding International, vol. 12, pp. 432-439, 1998.

[8] Ahsan M., Kim Y., Kim C., Kim J., Ashiri R., Park Y., Porosity formation mechanisms in cold metal transfer (CMT) gas metal arc welding (GMAW) of zinc coated steels, Science and Technology of Welding and Joining, vol. 21, pp. 209-215, 2016

[9] Raveendra J., Parmar R., Mathematical models to predict weld bead geometry for flux cored arc welding, Journal of Metal Construction, vol. 19, 1987.

[10] Wei E., Farson D., Richardson R., Detection of weld surface porosity by statistical analysis of arc current in gas metal arc welding, USA Journal of Manufacturing Processes, vol. 3, 2001.

[11] Vural M., Welding processes and technologies, Comprehensive Materials Processing, Elsevier, 2014, pp. 3-48.

[12] Kim J., Oh S., Ki H., A study of keyhole geometry in laser welding of zinc coated and uncoated steels using coaxial observation method, Journal of Material Processing Tech., pp. 451462, 2015.

[13] Mei L., Yan D., Yi J., Chen G., Ge X., Comparative analysis on overlapwelding properties of fiber laser and $\mathrm{CO}_{2}$ laser for body-in-white sheets, Mater. Design, vol. 49, pp. 905-912, 2013. [14] Akio H., Hirotaka T., Hirota Y., Nobutaka K., Kojiro F., Quantitative evaluation of softened regions in weld heat, Metallurgical and Materials Transactions A, vol. 30, pp. 21152120, 1999.

[15] Anawa E., Olabi A., Optimization of tensile strength of ferritic/austenitic laserwelded components, Optics and Lasers in Engineering, vol. 2008, pp. 571-577, 2008.

[16] Kayama E., Mizutani M., Laser weld ability of aluminium alloys, Trans JWRI, vol. 31, pp. 147-155, 2002.

[17] Feng G., Wang Y., Luo W., Hu L., Deng D., Comparison of welding residual stress and deformation induced by local vacuum elektron beam welding and metal active gas arc welding in a stainless steel thick-plate joint, Journal of Materials Research and Technology, 2021.

[18] Liu F., Tan C., Gong X., Wu L., Chen B., Song X., Feng J., A Comparative study on microstructure and mechnaical properties of HG785D steel joint produced by hybrid laser-MAG welding and laser welding, Optics \& Laser Technology, vol. 128, 2020 .

[19] Zhang S., Wang Y., Zhu M., Feng Y., Nie P., Li Z., Effects of heat source arrangements on laser-MAG hybrid welding characteristics and defect formation mechanism of $10 \mathrm{CrNi3MoV}$ steel, Journal of Manufacturing Process, vol. 58, pp. 563-573, 2020. [20] Zhang F., Liu S., Liu F., Zhang H., Stability evaluation of laser-MAG hybrid welding process, Optics \& Laser Technology, vol. 116, pp. 284-292, 2019. 